\title{
NOVAS TECNOLOGIAS, DISTRIBUIÇÃO DE RENDA E EMPREGO
}

Francisco José da Costa Alves ${ }^{*}$

\section{OBJETIVO}

O objetivo deste trabalho é o de, na perspectiva da Engenharia de produção, perceber as possibilidades de reversão das características atuais do crescimento econômico, incompatível com as necessidades de geração do emprego. Isto porque o desemprego e a crise do mercado de trabalho e da sociedade são, embora com características próprias, comuns a diferentes países. A Engenharia de Produção, como área do conhecimento que articula diferentes visões sobre as possibilidades de crescimento da produção, pode contribuir, se não para reverter, pelo menos para minorar os efeitos da crise da atualidade.

A crise contemporânea, tanto nos países do primeiro, quanto nos países do terceiro mundo, tem como principal desafio a geração de emprego. Passado o período de crescimento acelerado do pós-guerra, as taxas de crescimento da produção, do emprego e da renda, principalmente a partir da década de 1970, mantiveram-se em niveis absolutamente insuficientes para permitir o crescimento do mercado de trabalho. Mesmo os países que conseguiram taxas de crescimento elevadas durante um certo periodo, como o Japão, na década de

"Professor da Universidade Federal de São Carlos, Departamento de Engenharia de Produção. Doutor em Economia - UNICAMP. 
60, o Brasil, na década de 70, os países asiáticos, na de 70 e 80 , começaran, na década de 90, a amargar taxas insuficientes para gerar um mercado de trabalho compativel, tanto com seu crescimento populacional, quanto com a expansão da renda e do mercado de bens de consumo.

Não temos por objetivo apresentar uma perspectiva catastrófica a respeito do descompasso entre as taxas de crescimento populacional e as taxas de crescimento do mercado de trabalho. Pois mesmo nos países europeus, com baixas taxas de crescimento populacional, o crescimento do desemprego tem marcado a tônica das preocupaçôes quanto ao futuro, tanto por parte dos governos, quanto pelos partidos políticos, quanto pela própria academia.

\section{CARACTERISTICAS DA CRISE CONTEMPORÂNEA NO BRASIL}

A características mais evidente desta crise podem ser observada pela constatação, em diferentes países, que a produção de bens e serviços tem crescido vagarosamente, e acompanhada por uma diminuição da capacidade de absorção do mercado de trabalho. Ou seja, mesmo nos momentos em que a produção de bens e serviços cresce, ela não é acompanhada pelo crescimento do emprego, pela redução do número de desempregados e pela reserva latente'. Além disto, em diferentes países, o trabalho remunerado nos setores formalizados perdeu sua capacidade de direcionar as atividades humanas, de proporcionar referências sociais.

A importância destas questões são evidentes, porque a redução da capacidade de absorção do mercado de trabalho, assim como da capacidade do trabalho em direcionar as atividades humanas, leva à exclusão social. No Brasil são mais de 20 milhões de pessoas excluidas

${ }^{1}$ OFFE. C. "Trabalho e Sociedade - Problemas Estruturais e Perspectivas para o Futuro da Sociedade do Trabalho". Rio de Janeiro, Edições Tempo Brasileira, Biblioteca Tempo Universitário, $\mathbf{n}^{\circ} 85$, série Estudos Alemães, 1984, pag. 7. 
do mercado; primeiro do mercado de trabalho e, em consequiência, do mercado consumidor. $\mathrm{Na}$ sociedade capitalista, onde as possibilidades de obtenção de renda, de participação e de vida, estão vinculadas e determinadas pelo emprego e por sua remuneração, os desempregados são considerados fracassados. Nos países avançados, esta exclusão do mercado de trabalho é menor e menos traumatizante, isto em virtude da capacidade do Estado do Bem Estar Social em garantir condições de vida aceitáveis, via mecanismos públicos de distribuição de renda e/ou políticas compensatórios. Nos países mais atrasados, por outro lado, onde não há Estado de Bem Estar Social e, mais ainda, com a falência do próprio Estado, não existem políticas compensatórias, e a sobrevivência depende, exclusivamente, de mecanismos individuais de reprodução.

No mercado de trabalho, a distribuição dos riscos é absolutamente concentrada. Ao observarmos as parcelas da população que estão mais sujeitas ao desemprego e ao subemprego, e que obtêm menores rendas salariais, ocupam postos de trabalho restritivos e arriscam diariamente sua capacidade física de trabalho, veremos que estas parcelas correspondem a determinados gnupos sociais distinguidos por especificidades de sexo, de idade, de cor e de origem regional: no Brasil, a parcela da população onde mais se concentram tais riscos é a dos emigrantes do campo.

A agricultura tem como uma de suas caracteristicas básicas, no que tange à sua dinâmica populacional, a de geração de uma superpopulação relativa. Isto é, a sua capacidade imanente de produção crescente mas, concomitantemente, absorvendo uma quantidade menor de força de trabalho. $O$ crescimento da produtividade do trabalho na agricultura, pela incorporação do progresso técnico, torna gradativamente desnecessária uma parcela crescente de trabalhadores, seja para as atividades rurais propriamente ditas, seja mesmo para as atividades urbanas. Este fluxo pode ser acelerado pelo rítmo de incorporação do progresso técnico e pelas mudanças nas relações de trabalho. $O$ ritmo de incorporação do progresso técnico determina, de fato, a superpopulação relativa, ao passo que as mudanças nas relações de trabalho no campo não provocam, ao menos diretamente, desemprego: elas apenas 
expulsam, sob determinadas condições, um conjunto de trabalhadores que poderá ser reocupado, num momento posterior, numa nova relação de trabalho.

\section{O PADRÃO DE CRESCIMENTO AGROINDUSTRIAL BRASILEIRO}

Na década de 70 , houve na agricultura brasileira a ocorrência simultânea e conjugada daquelas duas forças. De um lado, cresceu o ritmo de incorporação do progresso técnico, em virtude de uma política deliberada do Estado de modernização conservadora da agricultura. Com esta política, foi provocado um crescimento da produtividade do trabalho na produção de determinados produtos e para determinadas faixas de produtores rurais; produtores em geral com mais terras, com maior renda e vinculados à produção de bens exportáveis ou mais articulados à produção industrial. De outro lado, mas com o mesmo sentido, mudaram aceleradamente as relaçóes de trabalho predominantes na agricultura, nas quais os trabalhadores permanentes e moradores nas propriedades (parceiros, meeiros, moradores, colonos, pequenos proprietários, posseiros etc.) foram expulsos do campo e reabsorvidos como trabalhadores assalariados, moradores das cidades. Por conta do progresso técnico, o balanço de expulsos e readmitidos sob novas relacões de trabalho foi desfavorável ao cmprego ${ }^{2}$. Isto é, ocorreu o crescimento do emprego de trabalhadores assalariados em quantidade menor do que o número de trabalhadores expulsos das propriedades. $O$ resultado final foi, pois. o contínuo decréscimo da quantidade de pessoas ocupadas na agricultura.

A agricultura no Brasil acelerou seu fluxo migratório do campo para as cidades, sendo que uma parcela menor foi readmitida no próprio campo, como trabalhadores assalariados, e uma outra parcela buscou nas atividades urbanas condições de reprodução. Se este fluxo migratório foi confortável e necessário para a expansão do capitalismo

${ }^{2}$ RICCI, R. ALVES, F. J. C. NOVAES, JR. Dinâmica do Mcrcado de Trabalho no Complexo Sucro-alcooleiro no Brasil. IPEA/PNUD, Relatórios Setoriais N. 15, Brasilia, DF, 1994. 
e da indústria nos seus primórdios - pela criação de superpopulação na cidade e pela conversão de uma grande parte desta $\mathrm{cm}$ exército industrial de reserva -, hoje, passada a fase de crescimento industrial acelerado, a existência deste fluxo é questionada c reconhecida como catastrófica. As atividades urbano-industriais têm se mostrado incapazes de absorver este contingente, mesmo com o crescimento da produção. Deste quadro tem emergido as teses, equivocadas c discricionárias, da necessidade de divisão do Brasil: "O Sul é o meu Pais". "República dos Pampas", que deixam intactas a necessidade premente de reaiização de uma reforma agrária.

Durante a década de 70, com as elevadas taxas de crescimento do Produto Interno Bruto, baseado no setor produtor de bens de consumo durável e na integração do parque industrial, através da constituição do setor produtor de bens intermediários, alimentou-se no Brasil a mística da possibilidade de crescimento com pleno-emprego. Este crescimento, mesmo a custa de um violento arrocho salarial, conseguiu, de um lado, integrar ao mercado uma grande parcela de trabalhadores e, de outro, constituir um mercado consumidor de alta renda. capaz de consumir os produtos industriais produzidos ${ }^{3}$. A década de 80 , com o esgotamento do processo, mostrou e jogou por terra a mística do pleno/emprego. Nela revelou-se, com evidente e dolorosa clareza, que o crescimento econômico da década anterior foi excludente, pois jogou na miséria uma parte substancial da população e produziu um mercado consumidor altamente concentrado.

O Brasil apresenta um mercado consumidor estruturado. grosso modo, em três estratos: um primejo, de aproximadamente 50 milhões de pessoas de alto poder aquisitivo, com renda superior a 20 salários mínimos por mês; um segundo, de aproximadamente $100 \mathrm{mi-}$ lhões de pessoas, com renda familiar de até 10 salários mínimos e. finalmente, um terceiro conjunto de pessoas, cerca de 20 milhões de

${ }^{3}$ TAVARES, M. C. Da Substituição de Importações ao C'apitalismo Financeiro. Rio de Janeiro, Editora Paz e Terra, 1973. 
cxcluídos. fora do mercado consumidor e com renda familiar inferior a I (um) salário minimo-1.

Este primciro conjunto de pessoas é a "nata" do mercado consumidor brasilciro. Para este conjunto restrito, mas de alto poder aquisitivo, é que se destina a produção de produtos agricolas e industriais diversificados. com una base de produção mais flexível e que permite produzir para gostos e consumos diferenciados. É necessário deixar claro. que embora o mercado consumidor brasileiro seja, na sua forma geral. pobre. apresenta um setor com caracteristicas de consumo de primciro mundo e que deseja ser integrado ao mercado consumidor mundial. Não \& por outra razão que as campanhas para a abertura e liberalização do mercado estão sendo empreendidas em ritmo cada vez mais acclerado. Estas objetivam permitir que os produtos produzidos

${ }^{4}$ MANCUSO, M. I. R. et alli (1994). Padrão de Vida e Pobreza em São Carlos, Relatório Preliminar de Pesquisa, xerox, UFSCar, São Carlos, SP. Neste Trabalho podemos perceber que em 1989 havia no Brasil a seguinte situação:

- 2.833.000 domicilios indigentes, $11,03 \%$ do total;

-5.783 .300 domicilios pobres, $22,52 \%$ do total e

$-66,6 \%$ de domicílios de famílias altas e médias

- de 106.808 .600 habitantes, $14,26 \%$ ou 15.226 .800 eram indigentes, $24,71 \%$ ou 26.341 .700 eram pobres e $61,03 \%$ ou 64.085.160, eram pessoas de renda média ou abastadas.

São considerados indigentes, famintos ou desnutridos, a população que tem renda apenas suficiente, em condições precárias para ter acesso à alimentação. São considerado pobres aqueles que têm renda para ter as necessidades básicas satisfeitas ou razoavelmente satisfeitas, tais como: alimentação, vestuário, habitação, material escolar, transportc, remédios, material de higiene e limpeza, lazer, bens de consumo duráveis. São considerados médios ou abastados aqueles que têm renda superior às necessidades básicas. 
por industrias de ponta no cenário mundial possam ser aqui vendidos dirctamente. sem taxações e a preços internacionais. $\mathrm{O}$ que. sem dúvida. irá divcrsificar a oferta e diminuir os custos dos produtos consumidos por este mercado concentrado e de alta renda. Existem poucos paises no mundo com um mercado consumidor deste tamanho. unificado. que fala mesma lingua.

Os setores da indústria voltados para este mercado consumidor de mais alta renda passaram a absorver quantidades decrescentes de trabalhadores. adaptando-se a um mercado consumidor reduzido $\mathrm{e}$ cxigente. tanto $\mathrm{cm}$ rclação à qualidade dos produtos. quanto em relação à difcrenciação. aos novos modelos ctc.. - acompanhando assim a onda mundial de esgotamento da produção de produtos de produção de massa. de base fordista de produção ${ }^{5}$. No mundo inteiro. não apenas no Brasil. esta indústria tornou-se mais competitiva com a adoção de novas tecnologias de base microeletrônica. de programas de racionalização da produção. de qualidade e produtividade. Com tais programas e tal perspectiva de concorrência. o crescimento da produção e da produtividade dar-sc-á com desemprego de significativa parcela dos trabathadores hoje cmpregados. A busca da produtividade. da flexibilidade e da qualidade. tem tido. como corolário. un todos os paises. uma menor absorção de trabalhadores nos setores que se modernizam.

Consideremos também que alguns segmentos da indústria brasileira. que produzem para este setor de mercado mais competitivo. de mais alta renda. devem buscar niveis de produtividade elevado. para adaptar-se aos padrōes da concorrência internacional. Qualquer politica de desaquecimento do nivel de investimentos neste setor levará. sem dúvida. à perda de competitividade para concorrentes externos. Porém. a questão que se coloca é: será que este paradigma deve ser geral para todos os segmentos de produção?

CORIAT. B. "Automação Programável: Novas Formas e Conccitos dc Organização da Produçào". in SCGMITZ. H. e CARVALHO. R. Q. Automą̧ão de Base Microeletrônica. Competitividade e Trabalho: A experiência Internacional. 


\section{DESAFIOS PARA A ENGENHARIA DA PRODUÇÃO}

$\mathrm{O}$ segmento do mercado consumidor que pode ser dinamizado através de uma política efetiva de distribuição de renda é o segundo segmento exposto acima: um segmento que unitariamente tem pouca renda, mas que, no seu conjunto, tem uma renda não desprezivel. As demandas deste mercado estão distantes das do primeiro grupo. Para este importa o consumo de massas, de bens e serviços de pouca diferenciação e baixo valor unitário, na medida em que é constituido pela população pobre, que tem enormes necessidades básicas ainda não satisfeitas, tais como: alimentação, habitação, escola, saúde, lazer, transportes etc. É um mercado consumidor cuja base de produção é, fundamentalmente, fordista, isto é, voltada para a produção de grandes quantidades de produtos padronizados, não diferenciados, para consumo de massa.

Neste sentido, consideramos que o desafio da Engenharia de Produção, no Brasil, neste momento, é o de adaptar o parque industrial, agrícola e de serviços para os desafios do século XXI. Estes desafios são, grosso modo, de um lado, acompanhar as transformações tecnológicas e organizacionais impulsionadas pela crise do paradigma taylorista/fordista de produção, e por outro, dar condições para o desenvolvimento dos setores produtores de bens e serviços de consumo de massa, que será revitalizado com o crescimento do nivel de emprego e pela distribuição de renda.

Neste momento, 1994, nos defrontamos, mais uma vez, com a possibilidade de decidirmos sobre dois Projetos de desenvolvimento da sociedade. De um lado, o que se propõe a dar continuidade ao modelo de desenvolvimento social excludente, voltado para os bens de produção modernos, integrados ao mercado mundial, iniciado em 1956, revitalizado e aprofundado com o golpe de 1964, e mantido pelos dois governos Civis (Sarney e Collor/Itamar). De outro, o Projeto que se propõe a iniciar um processo de desenvolvimento social não-excludente, voltado para a geração de emprego e distribuição de renda.

Caso saia vitorioso o primeiro Projeto, os desafios são os mesmos colocados neste momento: conseguir dar continuidade ao es- 
forço de adaptação do parque industrial, da agricultura e dos serviços aos padrões de qualidade e produtividade do pós-fordismo. É claro que estes desafios não são fáceis de serem alcançados, devido à escassez de capitais, à concorrência internacional, ao endividamento externo e às pressões sociais que não deve cessar. Caso, no entanto, o segundo projeto saia vitorioso, isto significará uma ruptura de continuidade com o processo de integração e as dificuldades serão também enormes, e maiores serão os desafios. Isto porque o setor mais exigido será exatamente o produtor de bens de consumo de massa, devido à sua capacidade imediata de geração de emprego e de produzir bens que atendam às necessidades da população que, com renda acrescida, virá integrar-se no mercado consumidor. Isto significará uma proposta de reorientação do incentivo produtivo, de forma a dar conta do consumo de massa e da geração de empregos, pondo fim a um mecanismo perverso de exclusão social.

Este segundo Projeto deverá atuar em três frentes:

1) a primeira será a da inserção no mercado de trabalho do contingente dos excluídos. Para isto será necessário uma campanha visando a "reciclagem profissional", a instituição do seguro desemprego e intermediação de emprego.

2) a segunda frente deverá dar conta do trabalho infor. mal, geralmente de baixa qualidade e sem capacidade de gerar renda suficiente para seu próprio sustento.

3) a terceira frente será a da reestruturação produtiva que tem gerado queda do emprego, deslocamento de postos de trabalho e alta rotatividade ${ }^{6}$.

$\mathrm{O}$ ataque as duas primeiras frentes deverá estar voltado para a criação postos de trabalho menos qualificados. Os setores que exigem menor qualificação profissional são exatamente os setores de produção

${ }^{6}$ MATTOSO, J. "Governo Lula vai criar 8 milhões de empregos", in Brasil Agora, São Paulo, ano II, n 61,05 a 20 de julho de 1994. 
de consumo de massa e a construção civil, do lado industrial. Na agricultura existe uma parte do setor, de base produtiva menos moderna, produtora de bens de consumo imediato, que gera uma grande quantidade de empregos, mas que depende de maior integração com o setor industrial à jusante da agricultura, ou de melhor integração ao mercado consumidor. No setor terciário, que é o que mais emprega, existem dois subsetores, que são básicos: um é o da infra-estrutura de turismo, outro é o de transportes ${ }^{7}$.

É claro que a terceira frente, que é a da reestruturação produtiva, já em curso, não pode ser negligenciada pelos motivos já apontados; pois visa dotar o setor industrial, voltado para o mercado de mais alta renda, de condições de qualidade e de produtividade necessárias para enfrentar a forte concorrência internacional. Esta reestruturação produtiva coloca um desafio novo e que interessa de perto à Engenharia de Produção: a terceirização de determinadas atividades.

O fenômeno da terceirização, se, de um lado, reduz postos de trabalho na empresa que terceiriza, os recria nas empresas médias e pequenas, as maiores geradoras de emprego, que serão incentivadas a atender a expansão da demanda por seus produtos. Será nestas empresas que a Engenharia de Produção deverá atuar, no sentido de expandir a produção nos níveis de produtividade e qualidade demandados $e$, ao mesmo tempo, aumentar o emprego e a formalização do trabalho e da sua relação com o mercado. $O$ problema do mercado de trabalho informal é sério, devido ao grande número de trabalhadores nele inseridos sem carteira de trabalho assinada, sem direito à previdência social, recebendo salários aviltados e submetidos a inúmeros riscos.

É importante ressaltar que a tendência à terceirização tem se dado, tanto no sentido de produzir itens que antes eram produzidos internamente, quanto no sentido da produção de novos produtos e serviços que passaram a ser necessários com o processo de reestruturação produtiva. Estes novos ramos de produção criados são, tanto de produtos e processos novos, que em geral requerem um nivel de qualificação 
elevado, quanto de setores antigos mas que existiam de maneira informal.

$\mathrm{Na}$ agricultura, setor chave no processo de geração de empregos, temos ainda inúmeros desafios a serem vencidos, mesmo para o setor integrado ao mercado consumidor de ponta, para o qual é necessário a introdução dos métodos de racionalidade que caracterizam a produção industrial recente. Não é por outra razão, que o setor agrícola passou a ser absorvedor de engenheiros de produção formados em nossas escolas. Passa a'ser fundamental o desenvolvimento de padrões de racionalidade de inspiração industrial adaptados às características da produção agrícola que, em sua base, tem uma organização de produção de caráter pré-fordista. $\mathrm{O}$ desafio é o de formar um profissional capaz de acompanhar todas as etapas da cadeia produtiva de base agricola, o chamado "agribusiness".

A agricultura se defronta com problemas que o profissional de Engenharia de Produção pode ajudar na sua resolução, devido à sua capacitação em métodos e processos. Estes problemas vão da redução das taxas de desperdício de insumos e produtos finais, à solução de problemas de logística envolvendo armazenagem e distribuição e de balanceamento de insumos que poderiam ser melhor enfocados a partir de técnicas da pesquisa operacional, passando por novos problemas de gestão da força de trabalho e redução dos riscos à saúde, que são bastante expressivos na agricultura ${ }^{8}$.

Existe outros setores da agricultura que foram excluídos do processo de modernização, embora tenham uma alta capacidade de formação de empregos, incentivem a retenção da força de trabalho no campo, e não necessitem de terra, mas sim de meios para vir a integrarse ao mercado em condições dignas de reprodução. Estes setores também são carentes de novas tecnologias de gestão e de processo, manejadas pelo engenheiro de produção, tais como: problemas de funcionamento de empresas; conhecimento da estrutura organizacional e de

${ }^{8}$ Programa do Curso de Engenharia de Produção Agroindustrial do DEP, UFSCar, São Carlos, 1993. 
relações inter-organizacionais - como o cooperativismo e outras formas de associativismo, necessárias para furar o cerco que estes setores da agricultura foram submetidos pelo crescimento dos oligopólios de base da produção agrícola; problemas de logística; de engenharia econômica, etc.

Caso se dinamize a produção para o atendimento do mercado consumidor de produtos de massa, será necessário ampliar a produção de matérias primas de origem agrícola, porque os grandes desafios da sociedade brasileira são a luta contra a fome e a exclusão social: o crescimento do mercado consumidor de massas tem impacto direto sobre o consumo de alimentos e vestuário. E tanto o setor alimentar, quanto o de vestuário, são atendidos por produtos industriais que se utilizam de matérias primas agrícolas.

Portanto, a proposta básica deste ensaio é a de incentivar a integração da Engenharia de Produção ao esforço de desenvolvimento do setor de produção de produtos de massa. Um setor que por adotar base tecnológica mais atrasada, tem maior capacidade de geração de empregos no curto prazo. Em suma, existe um enorme campo de atuação da Engenharia de Produção que não se restringe ao da produção de produtos diferenciados para atender a um mercado consumidor de alta renda.

Durante a última década, nós, profissionais da Engenharia de Produção, debruçamo-nos sobre as questões postas pela produção de produtos indiferenciados, com uma base de produção mais flexível, e que fugia aos conceitos básicos do paradigma fordista-taylorista. Acreditamos que o momento agora seja o de não apenas continuarmos a buscar soluções para os novos desafios, mas também o de revitalizar as questões básicas que o paradigma de produção fordista-taylorista buscava resolver, que era a produção a baixo custo de bens de consumo de massa e padronizados. Uma das poucas virtudes deste padrão de produção foi a de permitir a produção de massa para um mercado consumidor que se ampliava, proporcionando também o crescimento do nivel de emprego urbano industrial. Sabemos que já existe no Brasil um mercado consumidor numeroso, de baixa capacidade de consumo individual, mas de alta capacidade de consumo coletivo (como nos referi- 
mos acima). Para este mercado será necessário criarmos uma capacidade de produção que, neste momento, atende apenas marginalmente a este mercado de massa. Este setor tem também, caso dinamizado, elevada capacidade de absorção de trabalhadores, que é uma das características da produção massiva de base fordista-taylorista, se comparada com a nova forma de produção mais flexível de base microeletrônica.

\section{CONCLUSÕES}

É necessário ter claro que as perspectivas aqui anunciadas têm eficácia apenas no curto prazo. $\mathrm{O}$ curto prazo deve ser ressaltado porque o desenvolvimento tecnológico, com a incorporação do progresso técnico, tem gerado desemprego. Ou seja, na medida em que as empresas tornam-se mais produtivas e passam a incorporar progresso técnico, geram a dissolução de postos de trabalho e diminui a demanda por trabalhadores. A solução para este dilema no longo prazo está na redução da jornada de trabalho ou da remuneração das pessoas, mesmo que elas não trabalhem, visto que são prescindíveis na base produtiva moderna.

Esta é a solução que está sendo discutida nos países mais avançados, mas que mesmo lá esbarra na incapacidade de geração de recursos para remunerar as pessoas que não trabalham, dada a crise do Estado do Bem Estar Social. No Brasil, onde nunca existiu Estado do Bem Estar Social, e onde, lamentavelmente, tem grassado o ideário neoliberal de sucateamento do Estado, a alternativa é de, primeiro, brecar o processo de exclusão social, gerar emprego, gerar renda e gerar consumo, para depois, então, reduzir a jornada de trabalho e aumentar o tempo do lazer. No fundamental, a crise de geração de emprego não tem saída previsível nos marcos da produção com apropriação privada.

Estamos num momento ímpar da história. num momento onde já é potencialmente possível prescindir de muitas horas do trabalho quotidiano para a sobrevivência; o homem já pode(ria) abdicar de 
muitas horas de trabalho para dedicar-se ao que gosta de fazer ${ }^{9}$. Porém, nos limites da produção com apropriação privada, o homem ainda tem que comer o pão com o suor do seu rosto; ainda tem que se esgotar para viver - embora a ciência, a técnica e a tecnologia permitam-lhe, sempre potencialmente, prescindir de um esforco excessivo e de muitas horas de trabalho árduo.

${ }^{9}$ Esta é uma questão de extrema importância. Fui para ela alertado por Mauro Rocha Côrtes, do DEP/UFSCar, quando discutíamos este trabalho. 